\title{
BANCA PRIVADA Y VIVIENDA USADA EN LA CIUDAD DE MADRID
}

\author{
Víctor Jiménez Barrado \\ Departamento de Arte y Ciencias del Territorio. Universidad de Extremadura (España) \\ victorjb@unex.es \\ José Manuel Sánchez Martín \\ Departamento de Arte y Ciencias del Territorio. Universidad de Extremadura (España) \\ jmsanche@unex.es
}

\section{RESUMEN}

El número de viviendas usadas en poder de los bancos ha aumentado de forma notable en los últimos diez años como consecuencia de la crisis económica e hipotecaria. El considerable incremento del paquete de activos tóxicos inmobiliarios (más del 36\% entre el año 2012 y 2015) procede, en buena medida, de los impagos a la banca por parte de las familias. La ciudad de Madrid es una de las poblaciones más afectadas por este fenómeno, en la que se acumulan los desahucios día tras día. El presente estudio cuantifica y analiza, a través de la información que facilitan las inmobiliarias de las cinco principales entidades bancarias del país, esta bolsa de viviendas de segunda mano en la capital española. La localización de las mismas dentro del núcleo urbano permite conocer el grado de afectación por distritos. Por otro lado, nos hemos servido de la base de datos socioeconómicos de la Administración Local para determinar la incidencia social del posicionamiento de la banca privada. El análisis espacial a través de Sistemas de Información Geográfica ha revelado comportamientos anómalos de la banca en relación al mercado de compra-venta de viviendas usadas en la ciudad de Madrid.

Palabras clave: Activos tóxicos inmobiliarios; Crisis económica; Desahucios; Entidades bancarias; SIG; Vivienda usada; Madrid.

\section{ABSTRACT}

\section{Private banking and second-hand housing in the city of Madrid}

The number of second-hand homes held by banks has increased significantly in the last ten years as a result of the economic and mortgage crisis. The considerable increase in the toxic real estate assets package (more than 36\% between 2012 and 2015) comes largely from banking defaults by families. The city of Madrid is one of the municipalities most affected by this phenomenon, in which evictions accumulate day after day. This study quantifies and analyses, through the information provided by the real estate departments of the top five banks in the country, this housing pool of second-hand homes in the Spanish capital. Their location within the city allows a knowledge of the degree of affectation by districts. Furthermore, we used the Local Administration's socio-economic database to determine the social impact of the positioning of private banking. The maps produced by means of Geographic Information Systems have revealed anomalous behaviour of banks in relation to the second-hand housing market in the city of Madrid.

Key words: Real estate toxic assets; Economic crisis; Evictions; Banks; GIS; Second-hand home; Madrid.

\section{INTRODUCCIÓN}

Las consecuencias de la que en principio fue una crisis financiera e hipotecaria han alcanzado a todos los sectores sociales y económicos, convirtiendo el problema en global. En nuestro país, la recesión ha 
incidido con especial crudeza sobre las familias con menos recursos, fruto de un agravamiento de la crisis provocado por la exposición de la banca pública y privada al "boom inmobiliario" español.

Tras el estallido de la burbuja inmobiliaria española, la economía nacional sufrió un importante estancamiento debido al gran peso del sector de la construcción, que llegó a alcanzar el 12,47\% del PIB en 2008 y a ocupar al 12,84\% de los trabajadores en 2007 según datos del Instituto Nacional de Estadística [INE]. Hoy en día, su influencia se estima en el 5,20\% del PIB, dando ocupación al 5,89\% de los trabajadores. Debido a esta decadencia económica, precedida por un periodo, explicado por Calderón (2002), de expansión bursátil de las principales empresas constructoras e inmobiliarias del panorama nacional, la tasa de paro pasó del 7,93\% en el segundo trimestre de 2007 hasta el 21,18\% registrado en el tercer trimestre de 2015, con picos de hasta el 26,94\% en el primer trimestre del año 2013.

El poder adquisitivo de las familias ha descendido notablemente durante el periodo de recesión, desde los 15.504 euros de Renta Disponible Bruta de los Hogares (per cápita) en 2008, hasta los 14.414 euros de 2012 (último dato publicado por el INE). Fruto de ello, el balance entre vivienda en propiedad y vivienda alquilada se ha ido decantado hacia la segunda, aunque todavía con un predominio claro de la primera $(78,9 \%)$. En los últimos diez años, a tenor de los resultados extraídos de los Censos de Población y Vivienda, el número de viviendas en alquiler ha crecido un $51,1 \%$, con lo que alcanza 2.438.574 inmuebles. Aun así, tal y como exponen Ortega, Rubio y Thomas (2011), se aprecian diferencias notables en el comportamiento de los españoles y el resto de europeos, ya que mientras en España la cuota del alquiler alcanzaba sólo el 11\% en 2007, en Europa rozaba el 30\% (valores ya conocidos en 1970 a nivel nacional).

La compra de viviendas ha sido una de las tradicionales inversiones refugio en España, y es que "es la principal (y en la mayor parte de los casos la única) oportunidad de ahorro e inversión (enriquecimiento) para la mayoría de los hogares" (Vinuesa, De la Riva y Palacios, 2009, p. 506). Sin embargo, se está produciendo un descenso importante en la adquisición de este tipo de inmuebles. Esta caída se vislumbra en la evolución de las hipotecas concedidas, cuyo número estuvo en declive desde el año 2006 (bajada del $85 \%$ ), y actualmente experimenta leves crecimientos desde agosto de 2013, fecha en la que este registro alcanzó su mínimo. Hoy en día, una de cada tres viviendas principales tiene pagos pendientes, una cifra que dobla la registrada en el Censo de 2001.

La coyuntura socioeconómica provoca que la morosidad de las familias españolas haya aumentado exponencialmente durante la crisis. El número de ejecuciones hipotecarias sobre fincas urbanas en España ascendió hasta 70.078 en 2014. Las provincias más afectadas fueron Barcelona (12,72\%), Valencia (7,62\%) y Madrid $(6,21 \%)$. Si nos centramos en aquellas que se produjeron sobre personas físicas, el número total es de 44.682 ejecuciones hipotecarias, manteniéndose las provincias más afectadas: Barcelona (16,27\%), Valencia (9,32\%) y Madrid (7,82\%).

La bolsa de viviendas en poder de los bancos sigue un imparable aumento desde el año 2007. Durante el periodo de expansión económica, buena parte de los créditos hipotecarios cubrían más del $80 \%$ del precio de la vivienda. Según Naredo (2009), "esta enorme liquidez barata dio rienda suelta a la burbuja inmobiliario-financiera y al espectacular endeudamiento de hogares y empresas" (p. 129). La sobrevaloración de estos activos inmobiliarios produjo un importante endeudamiento de los hogares, cuyas hipotecas superaban el coste real del inmueble. Ante la imposibilidad de pago por parte de algunas familias, los desahucios se están multiplicando. Esta situación deja a las personas en una situación crítica, puesto que tras la caída de precios de la vivienda, la venta del bien no garantiza saldar la deuda hipotecaria.

La sobreexposición de la banca española a los activos tóxicos inmobiliarios hizo necesario un rescate bancario, apoyado en fondos provenientes de la Unión Europea en el que el Estado español podría gestionar hasta 100.000 millones de euros. Mediante esta ayuda financiera, España acometió una restructuración bancaria a través del Fondo de Restructuración Ordenada Bancaria [FROB] y la Sociedad de Gestión de Activos Procedentes de la Restructuración Bancaria [Sareb],

constituida como sociedad anónima (al 45\% con fondos públicos y al 55\% con capital privado) el

28 de noviembre de 2012 para liquidar, en un plazo máximo de quince años, los activos financieros

e inmobiliarios procedentes de los bancos españoles que habían recibido ayudas públicas (Calvo y

Martín de Vidales, 2014, p. 549)

y regulada jurídicamente por el Real Decreto 1559/2012.

Por lo tanto, esta sociedad es la encargada de gestionar la venta de los activos inmobiliarios pertenecientes a los bancos, cuyo valor total se estima en 11.089 millones de euros a fecha de 31 de diciembre de 2014 según el último Informe anual de la Sareb. Por su parte, los bancos crearon ex 
profeso unas inmobiliarias propias para la gestión y venta de parte de sus activos. Este es el caso de las inmobiliarias Altamira (Banco Santander), ANIDA (BBVA), Servihabitat (CaixaBank), Haya Real Estate (Bankia) y Solvia (Banco Sabadell), entre otras.

El estudio de Madrid, capital y ciudad más poblada de España ( 7\% de la población nacional), resulta de gran interés para comprender cómo se sitúa la banca española en el mercado de la vivienda usada dentro de una gran urbe. No en vano, esta ciudad registra una de las mayores bolsas de estos activos inmobiliarios propiedad de los bancos, en gran parte provenientes de desahucios. La Comunidad de Madrid aglutina el 12,3\% de las viviendas y 14,3\% del valor de los activos inmobiliarios propiedad de la Sareb. Además, fue la tercera región por nivel de ventas (11,3\% del total) y la primera por recaudación (28,7\% del total) en el año 2014, lo que confirma la actividad de su mercado inmobiliario. La actual coyuntura económica dificulta la venta de estos inmuebles, aunque las perspectivas de crecimiento son buenas ya que tanto el número de transacciones de vivienda usada (4.765 operaciones en el tercer trimestre de 2008, según datos del Ministerio de Fomento) como su precio (Índice de Precios de la Vivienda de 53,408 en el cuarto trimestre de 2013, según datos del INE), han tocado fondo en la Comunidad de Madrid.

El presente estudio gira en torno a dos líneas fundamentales. En primer lugar, la caracterización del mercado de vivienda usada en la ciudad, con especial atención al segmento de viviendas en manos de la banca; y en segundo lugar, la elaboración de una somera radiografía socioeconómica y demográfica de la ciudad de Madrid (tomando como referencia espacial los distritos) que sirva de apoyo a la explicación de las repercusiones sociales que ha tenido el comportamiento de las entidades bancarias. Por tanto, el objetivo principal del estudio es descubrir la interrelación entre estos dos aspectos, lo que nos permitirá definir el posicionamiento de las entidades bancarias dentro de un mercado muy amplio y las relaciones causales existentes entre la situación actual y los procesos que nos han llevado hasta aquí.

\section{METODOLOGÍA}

El presente estudio ha requerido la utilización de una amalgama de bases de datos alfanuméricas y cartográficas de distinta escala, pero con datos aplicables a nivel municipal, para su incorporación a los Sistemas de Información Geográfica y posterior análisis geoestadístico.

\subsection{Fuentes cartográficas y de información socioeconómica e inmobiliaria}

La identificación de características de índole social, demográfica y económica a escala de detalle distrital nos obliga a acudir a las bases de datos municipales. El Ayuntamiento de Madrid ofrece esta información a través del Barómetro de Economía de la Ciudad de Madrid (2008) y la sección estadística de su portal web. Además de estos datos, proporciona registros de diferentes variables que nos pueden ayudar a caracterizar el mercado de la vivienda por cada distrito, como el precio medio del $\mathrm{m}^{2}$ de vivienda (nueva y usada) y su evolución, la superficie media de las viviendas usadas, el número de transacciones totales de vivienda (nueva y usada) y valor medio de las hipotecas concedidas. A su vez, estos registros han sido complementados con los referidos al número de viviendas principales, secundarias o vacías procedentes del Censo de Población y Viviendas de 2011.

El Instituto de Estadística de la Comunidad de Madrid, a través de su Sistema de Información Territorial "Nomecalles", ofrece información en formato Shapefile. Entre las capas utilizadas, destacan aquellas cuya topología se corresponde con puntos (bocas de metro, paradas de autobús, centros comerciales, centros de salud, centros educativos, etc...). Esta información sirve para determinar el atractivo inmobiliario potencial de cada inmueble en función de los equipamientos y servicios cercanos.

La información relativa a las viviendas usadas pertenecientes a los bancos se ha extraído de los portales web de sus propias inmobiliarias ${ }^{1}$. Por lo tanto, hemos trabajado con cinco buscadores: Altamira (Banco Santander), ANIDA (BBVA), Servihabitat (CaixaBank), Haya Real Estate (Bankia) y Solvia (Banco Sabadell).

Los datos recopilados para cada inmueble hacen referencia a la vía en que están ubicados, el portal, su superficie total construida, el número de habitaciones y el número de aseos de que dispone. En este análisis, la búsqueda de inmuebles se ha limitado a viviendas usadas, excluyendo las restantes tipologías. Posteriormente, éstas viviendas se han georreferenciado mediante ArcMap 10.2 de ESRI a través de puntos a los

1 La recopilación de los datos se produjo entre el 6 y el 20 de julio del año 2015. 
que se asociaban, uno a uno, los registros antes mencionados. Las características de cada buscador difieren bastante, así como la información que facilitan para la localización precisa del inmueble. Por regla general, y debido a que el principal propósito de estos portales es, en teoría, efectuar una venta lo más rápida posible, la información proporcionada es bastante completa. En aquellos casos en que la ubicación del inmueble es más complicada (generalmente por la omisión del número de portal o bloque), complementamos la búsqueda sirviéndonos de las fotografías expuestas en el buscador y la herramienta Street View de Google Maps.

La base cartográfica corresponde al INE (división distrital de Madrid), a la Dirección General del Catastro (parcelas catastrales), con información relevante en cuanto a la edad de la edificación, y al Centro Nacional de Información Geográfica, gracias a su producto Cartociudad (callejero y numeración de los portales).

\subsection{Proceso metodológico}

El análisis de la relación espacial entre las variables socioeconómicas e inmobiliarias requiere la conjunción de ambas dentro de un Sistema de Información Geográfica. Tras la inserción de estos datos en la cartografía distrital de Madrid, hemos georreferenciado cada una de las viviendas y relacionado todas las variables entre sí. A través del análisis espacial de elementos cartografiados con una probable impronta en el precio de la vivienda, como puede ser su grado de conexión intra-urbana, la proximidad a zonas comerciales, sanitarias o de centros educativos, aspirábamos a explicar la asignación de precios que los bancos habían realizado.

Para simplificar todas las variables espaciales en un solo dato numérico, hemos realizado un índice de atractivo inmobiliario que mide en qué grado del mismo se encuentra cada inmueble según su distancia a los elementos cartografiados. De esta manera, hemos calculado (herramienta "Distancia de punto") para cada uno de los inmuebles un valor en función de su distancia a la parada de metro más cercana, el instituto más próximo, el centro comercial más inmediato, etc...Tomando como referencia los registros máximos y mínimos que nos encontrábamos en cada una de las variables, hemos establecido unos rangos para cada variable, a los que hemos asignado un valor que iba del 1 (menor influencia, mayor distancia) al 5 (mayor influencia, menor distancia). Posteriormente, conscientes de la desigual impronta de unos elementos y otros, hemos ponderado los resultados multiplicando el resultado de cada variable por un valor que expresara su posible grado de influencia en el precio de la vivienda ${ }^{2}$. Una vez determinados los valores del índice correspondientes para cada uno de los 734 inmuebles, hemos incorporado esta información a nuestros análisis como una variable espacial más.

Las pruebas realizadas a través del paquete de herramientas de análisis geoestadístico del software ArcMap 10.2. han resultado poco satisfactorias, por lo que hemos tenido que abordar la explicación de la muestra de datos a través de estadísticos más simples, pero no por ello menos válidos. Si bien, estos análisis no nos permiten descifrar el modelo de asignación de precios de los bancos a sus inmuebles, sí que son efectivos para determinar su posicionamiento en relación con el mercado de la vivienda usada en la ciudad.

Una vez construida nuestra base de datos, y asociada ésta a la cartografía de puntos generada, hemos realizado una regresión exploratoria de las variables contempladas, definiendo el precio como variable dependiente, y el resto como variables explicativas. En este grupo de variables hemos incluido aquellas características propias de los inmuebles como la superficie construida, el número de habitaciones y baños, e incluso su edad, mientras que por otro lado, hemos añadido al proceso elementos externos asociados a su ubicación, como su conectividad, atractivo inmobiliario de zona o nivel socioeconómico.

Los resultados arrojados por el paquete estadístico no fueron los esperados, ya que entre los modelos propuestos, el R2 ajustado más elevado no llegaba a 0,70 a pesar de estar éste compuesto por seis variables. Este valor podría considerarse válido de no ser excesivo el peso de la variable "superficie de los inmuebles" dentro del modelo (el modelo compuesto únicamente por la variable "superficie de los inmuebles" consigue un R2 ajustado de 0,62). Por lo tanto, podemos afirmar que el resto de variables no suponen un aporte importante a la hora de explicar la muestra. De hecho, si excluimos la variable "superficie de los inmuebles" del análisis, sólo llegamos a un R2 ajustado de 0,38 con modelos muy complejos de hasta cinco variables. Es de destacar la ínfima presencia dentro de los modelos con un ajuste más elevado de la variable generada y denominada "Índice de atractivo inmobiliario".

2 Las ocho variables estudiadas se dividen en cuatro grupos. Por un lado, el grado de conexión intra-urbana compuesto por la distancia a la boca de metro más cercana (Coeficiente de Ponderación $x^{*} 2$ ) y la distancia a la parada de autobús más próxima $(C P$ x* 1 ). De otro lado, la influencia del sector socio-sanitario $\left(C P x^{*} 1,75\right)$. En tercer lugar, el influjo del comercio, con coeficientes de ponderación variables según sean grandes centros comerciales $\left(\mathrm{CP} \mathrm{x}^{*} 1,75\right)$ o hipermercados $\left(\mathrm{CP} \mathrm{x}^{*} 1,5\right)$. Por último, la incidencia del sector educativo: Infantil $\left(\mathrm{CP} x^{*} 1,75\right)$, Primaria $\left(C P x^{*} 1,75\right)$ o Secundaria $\left(\mathrm{CP} x^{*} 1\right)$. 
El desconocimiento de las variables idóneas para la explicación del modelo, nos impide continuar con análisis más avanzados como la Regresión Geográficamente Ponderada. El poco peso de las variables externas, entendidas éstas como las que caracterizan la zona en que se ubica el inmueble, nos lleva a pensar en una horquilla de precios condicionada mayoritariamente por aspectos propios del inmueble como su superficie o número de habitaciones, aunque al mismo tiempo nos índica la ausencia de variables relevantes no contempladas en el estudio. El estado de conservación de los inmuebles, así como la calidad de sus instalaciones, son aspectos no considerados por la inexistencia de datos provenientes de fuentes oficiales o extraoficiales, así como la imposibilidad de acceder a ellos a través de otras vías. Por otro lado, hemos descartado la utilización de otros condicionantes por la incapacidad para determinar si éstos pudieran ser positivos o negativos, y en qué grado afectarían al atractivo de los inmuebles.

Entre los análisis espaciales complementarios aplicamos un análisis de punto caliente (Gi* de Getis $\mathrm{Ord}^{3}$ ) sobre la capa de viviendas basado en la variable precio (Figura 1). El resultado nos mostró la concentración de viviendas de precio elevado en los distritos centrales, y dos concentraciones de inmuebles de precio relativamente bajo en los distritos del sur (Distritos de Villaverde y Puente de Vallecas). Este análisis, en el que casi un $65 \%$ de la muestra no conseguía valores significativos ( $<90 \%$ de confianza), sólo supone una aproximación leve a la distribución espacial de los precios de la vivienda, ya que no permite una visión global de esta variable.

Figura 1. Análisis de punto caliente (Hot Spots Gi* de Getis Ord) basado en el precio de los inmuebles en manos de las entidades bancarias.

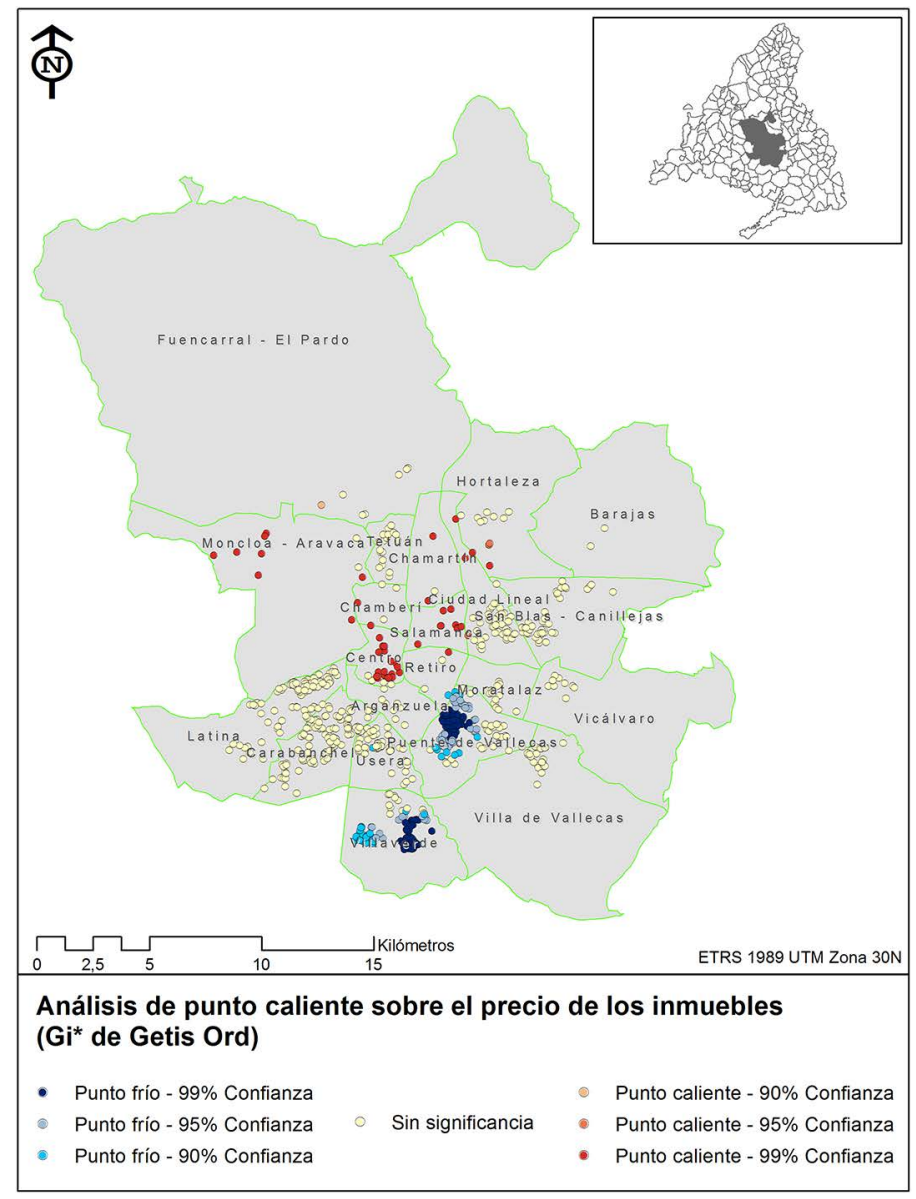

Fuente: inmobiliarias Altamira, ANIDA, Servihabitat, Haya Real Estate y Solvia. Elaboración propia.

3 Dado un conjunto de entidades, este análisis estadístico sirve para determinar agrupaciones espaciales de las mismas en función de sus valores. Estos conjuntos quedan determinados por el valor P (que muestra la probabilidad del modelo), que debe ser significativo (>90\% de confianza), y por la puntuación Z (equiparable a la desviación estándar) de sus puntos. Este último parámetro determinará si nos encontramos ante un punto caliente (valores positivos) o un punto frío (valores negativos). 
El análisis de la distribución de precios a través de la autocorrelación espacial I de Moran ${ }^{4}$ desestima la hipótesis nula (Gráfico 1), es decir, la distribución de precios de vivienda no presenta aleatoriedad. El índice resultante es bajo $(0,193)$, lo cual muestra un grado de autocorrelación espacial débil. Sin embargo, una puntuación P muy elevada $(3,429)$ indica una agrupación de los registros altos muy fuerte. A esto se une un valor $\mathrm{P}$ extremadamente bajo, lo que significa una ínfima probabilidad de que este modelo agrupado se deba al azar. La falta de correlación se puede apreciar previamente en la escasa concordancia entre el índice de atractivo inmobiliario (variable espacial) y el precio de la vivienda usada (Gráfico 2).

Este resultado impide la consecución de uno de nuestros objetivos, pero al mismo tiempo, confirma la existencia de variables no contempladas que determinan el precio y aumentan la dificultad, cerciorada por algunos autores como Duque, Velásquez y Agudelo (2011), para determinar un modelo si omitimos (en este caso por la imposibilidad de acceder a la información) variables relevantes.

Por lo tanto, nos hemos enfrentado a dos hechos que han impedido uno de nuestros objetivos: por un lado, la ciudad de Madrid cuenta en todos sus puntos con un alto grado de conectividad urbana a través de su sistema radial de conexiones y un nivel de equipamientos educativos, comerciales y sanitarios muy similar. Por otro lado, y como principal escollo, nos ha sido imposible conocer el estado de los inmuebles, así como sus equipamientos internos. El desconocimiento de esta variable imposibilita un análisis espacial más complejo, que nos revele la política de asignación de precios que han seguido los bancos.

Gráfico 1. Nivel de significancia estadística del índice I de Moran elaborado sobre el precio de la vivienda usada

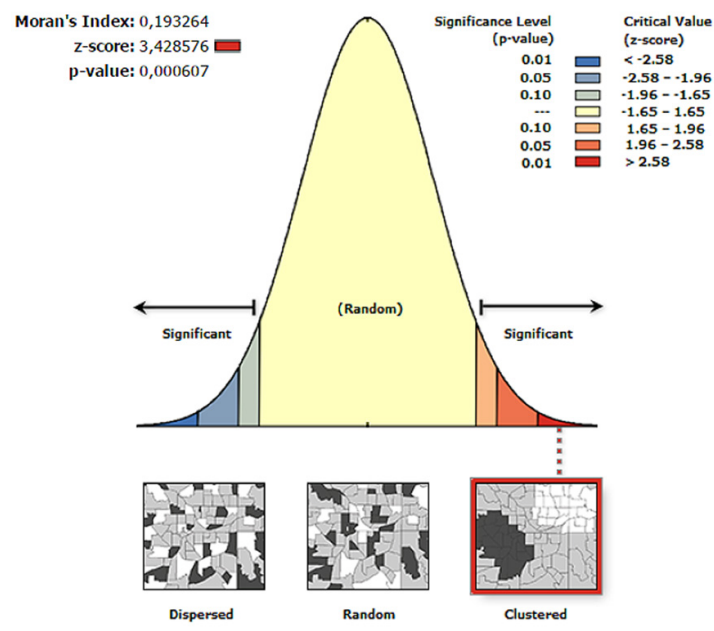

Fuente: Resultado extraído del software ArcMap 10.2. Elaboración propia.

No obstante, en nuestros análisis de prueba, tales como la autocorrelación espacial I de Moran o los análisis de punto caliente $\mathrm{Gi}$ * de Getis Ord, queda refrendada una alta variabilidad de los precios. Este hecho se debe probablemente a la ausencia de información relativa al estado de los inmuebles. Una falta de información que llega incluso a los propietarios de los mismos (entidades bancarias), ya que son muchas las viviendas tapiadas (provenientes de desahucios) por las entidades bancarias de forma apresurada y sin previa valoración, para evitar sufrir una ocupación ilegal. De ellos, la información disponible se limita a la descripción de la zona en que se ubican, así como el número de estancias que los componen.

Incluso eliminando la influencia de algunas variables, como la superficie o el número de habitaciones (realizando análisis sesgados por horquillas de tamaño del inmueble o reduciendo el estudio a aquellas viviendas de tres habitaciones, por otro lado, las más numerosas), no hemos conseguido establecer una relación espacial coherente de precios, puesto que el estado de los inmuebles, desvaría por sí solo, y en alto grado, el precio de una vivienda. Por este motivo, hemos optado por continuar con un análisis espa-

4 Este análisis geoestadístico relaciona la localización de los puntos con sus valores de forma simultánea. En él se calcula el índice I de Moran, que mide la autocorrelación espacial de los valores $(-1,+1)$. Este índice valida su significancia en función de un valor P (que mide la probabilidad), mientras que una puntuación Z (equiparable a la desviación estándar) determina la existencia de agrupaciones de valores altos o bajos. A través de este análisis podemos comprobar la aleatoriedad o agrupación en la distribución espacial de los valores. 
cial vinculado a espacios predefinidos como los distritos, en una línea de trabajo similar a la seguida en otros estudios previos (Jiménez, 2015).

Gráfico 2. Relación entre el precio de la vivienda usada $\left(€ / \mathrm{m}^{2}\right)$ y el índice de atractivo inmobiliario en Madrid.

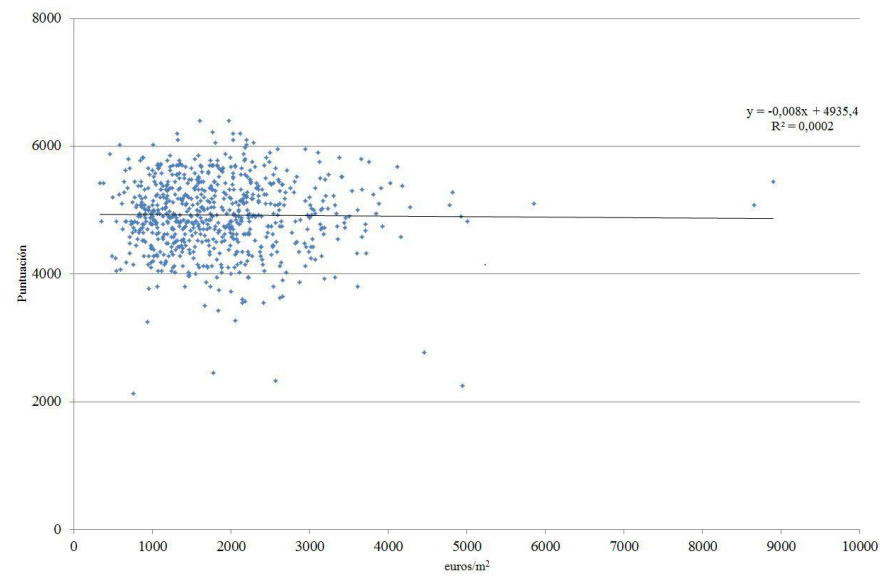

Fuente: inmobiliarias Altamira, ANIDA, Servihabitat, Haya Real Estate y Solvia. Elaboración propia.

\section{RESULTADOS}

La ciudad de Madrid, al igual que todas las grandes ciudades del mundo, presenta desigualdades entre los distritos que las componen. En el caso de la capital española, el modelo norte-sur, entendido éste como la diferenciación socioeconómica entre las zonas septentrionales más ricas y las zonas meridionales más pobres, se mantiene con algunas particularidades.

La población de Madrid es de 3.165.235 personas según los últimos datos publicados por el INE (1 de enero de 2014), siendo por tanto, la urbe más poblada de España. En la última década, la capital ha sufrido un estancamiento demográfico en favor de las ciudades satélites colindantes, ya que su ritmo de crecimiento se cifra en un $0,13 \%$ desde el año 2004, mientras que municipios como Alcobendas $(+11,84 \%)$, Getafe $(+10,94 \%)$, Alcorcón $(+8,78 \%)$, Leganés $(+4,52 \%)$ y Fuenlabrada $(+1,77 \%)$, han seguido incrementando su población a un ritmo superior durante el mismo periodo.

Figura 2. Evolución demográfica (2004-2014) de los distritos madrileños.

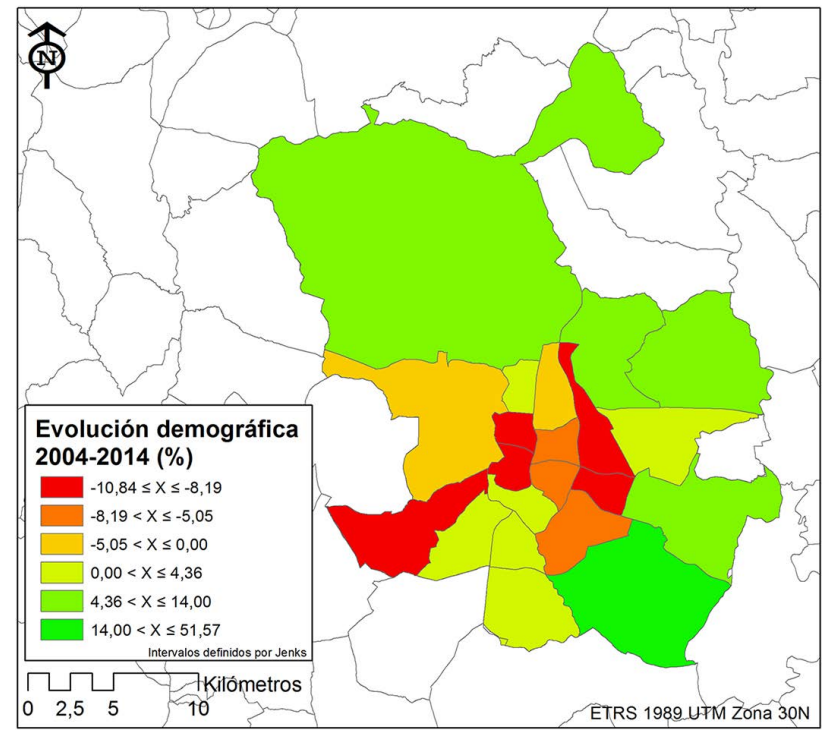

Fuente: Instituto Nacional de Estadística. Elaboración propia. 
A pesar de esta situación, la ciudad ha experimentado trasvases demográficos a nivel interno en los últimos diez años. En la Figura 2 observamos como los mayores incrementos poblacionales (por encima del 4,36\%) se registran en aquellos distritos más periféricos, aunque con notables excepciones como la presentada por el distrito Latina. Entre todos ellos destaca la Villa de Vallecas, con un crecimiento del 51,57\% entre 2004 y 2014, así como Vicálvaro, Hortaleza, Fuencarral-El Pardo y Barajas, todos ellos por encima del $10 \%$ de incremento poblacional. La evolución demográfica de los distritos más cercanos al centro se mueve entre pérdidas discretas (Tetuán y Arganzuela) y mermas poblacionales notables alrededor del 10\% (Centro y Chamberí), posiblemente inducidas por procesos de gentrificación.

A nivel económico, los distritos con menor renta se identifican con aquellos que registran una mayor tasa de paro (Figura 3). La brecha socioeconómica entre los distritos situados al sur (tradicionalmente los más humildes) y los situados al norte se ve acentuada por la actual recesión, tal y como exponen Méndez y Prada-Trigo (2014). Los distritos madrileños que surgieron en los años sesenta y setenta, consecuencia del éxodo rural que experimentó España, y crecieron a un ritmo vertiginoso acogiendo efectivos poblacionales poco cualificados, son hoy los que se sitúan a la cola en cuanto a nivel de renta (Villaverde, Puente de Vallecas, Usera, Villa de Vallecas y Carabanchel), presentando además "claros síntomas de obsolescencia" (Temes, 2014, p. 121) en cuanto a características físicas y sociales, prestación de servicios públicos y nivel de accesibilidad.

Figura 3. Nivel de renta (2005) y tasa de paro (junio 2015) por distritos de Madrid.

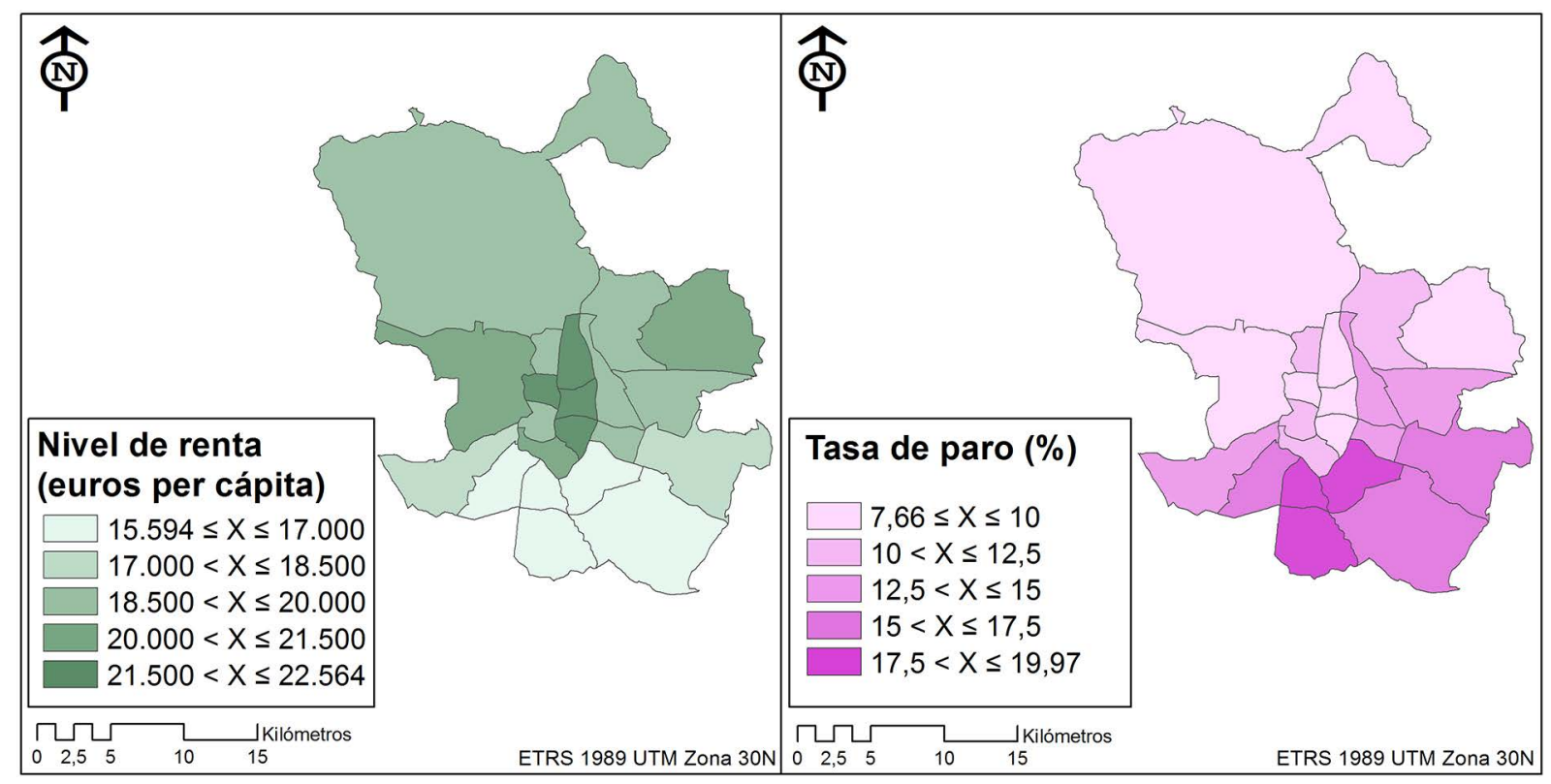

Fuente: Barómetro de Economía de la ciudad de Madrid (2008) y la Encuesta de Población Activa (2015). Elaboración propia.

Madrid es el mercado inmobiliario municipal más importante del país. La capital, con una superficie total de 604,46 kilómetros cuadrados, alberga 1.530 .700 viviendas (0,48 viviendas por habitante) según el Censo de Población y Viviendas 2011. Del total de viviendas, el 86,26\% son viviendas principales, el $3,74 \%$ secundarias y el resto, $10 \%$, están vacías. Las viviendas usadas que las entidades bancarias han puesto en venta se encuentran en este último segmento, junto a otras viviendas pertenecientes a particulares u otras entidades de distinta naturaleza. Por distritos, estas 153.050 viviendas se localizan principalmente en aquellos centrales y meridionales de Salamanca $(8,59 \%)$, Latina $(8,42 \%)$, Puente de Vallecas $(8,01 \%)$, Carabanchel $(7,88 \%)$ y Centro $(7,31 \%)$, sin representar las viviendas vacías un peso inferior al $10 \%$ sobre el total de cada distrito en ninguno de estos cinco.

La presencia de viviendas vacías no garantiza un comportamiento paralelo del mercado inmobiliario, ya que esto nos llevaría a deducir que a más viviendas vacías le correspondería un mayor número de transacciones inmobiliarias. Sin embargo, aunque esta relación es positiva, no presenta una correspondencia exacta entre el número de viviendas vacías y la cantidad de compraventas. Este hecho se observa en los distritos meridionales, los cuales presentan un alto porcentaje de viviendas vacías al que no acompaña un 
elevado número de transacciones. Estos bajos valores se mantienen en todas las secciones de la periferia incluso si tenemos en cuenta las transacciones de vivienda nueva (Figura 4). El nivel de renta es uno de los factores que nos lleva a explicar las diferencias en el volumen de transacciones inmobiliarias.

Figura 4. Precio de la vivienda usada por distritos y transacciones inmobiliarias de vivienda (datos año 2014).

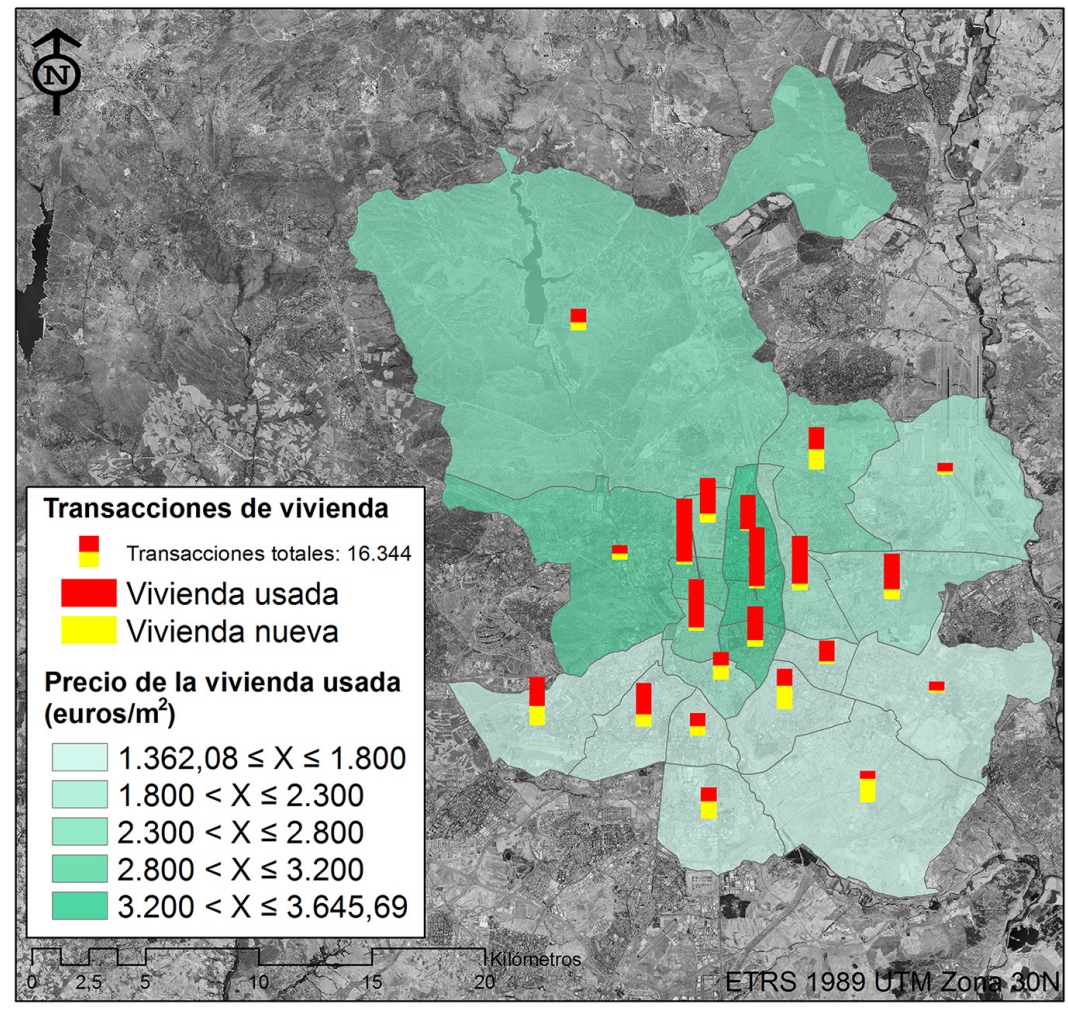

Fuente: Ayuntamiento de Madrid. Elaboración propia.

Si prestamos atención a la evolución del precio de la vivienda usada por distritos (Gráfico 3), podremos observar una tendencia similar de los mismos, a pesar de los distintos niveles que presentan. Desde el inicio de siglo, los precios crecen ininterrumpidamente hasta alcanzar su valor máximo entre el año 2006, en los distritos más humildes, y los años 2007 y 2008, en aquellos más caros. Inmediatamente después, se registra una caída generalizada de precios que en los distritos del sur, supone volver a valores cercanos, cuando no inferiores, a los de principio de siglo.

Gráfico 3. Evolución del precio de la vivienda usada (€/m²) por distritos (2001-2014).

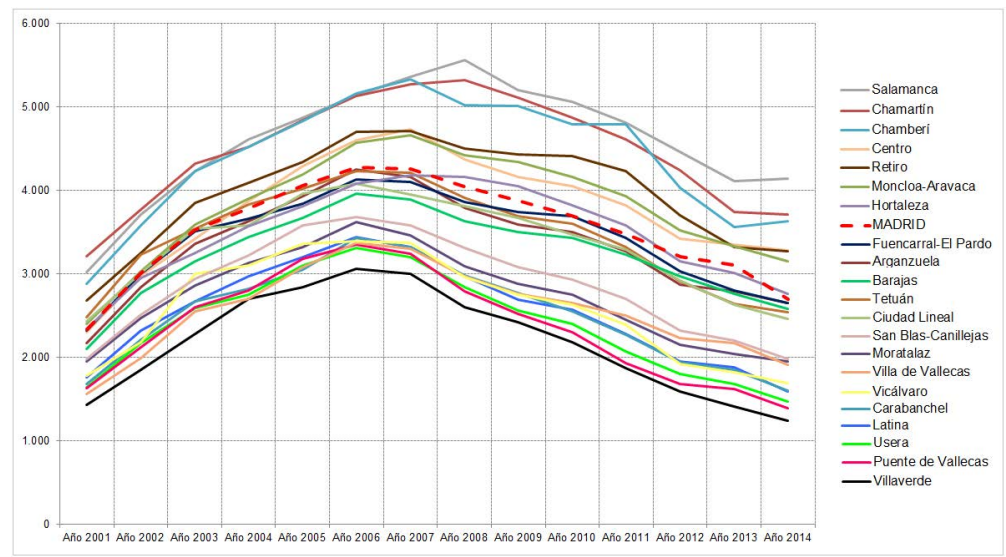

Fuente: Ayuntamiento de Madrid. Elaboración propia. 


\section{DISCUSIÓN DE RESULTADOS}

Las entidades bancarias se han convertido en el principal actor dentro del mercado inmobiliario de viviendas usadas en la ciudad de Madrid. Las causas que nos han llevado hasta esta situación, antes citadas, han empujado a la banca privada a gestionar directamente una ingente bolsa de activos inmobiliarios de difícil venta dentro de la coyuntura económica que atraviesa el país.

El posicionamiento de la banca privada sobre el mercado de vivienda no surge de una situación normal, puesto que la posesión de activos inmobiliarios no se encuentra entre las principales opciones de negocio para estas empresas, sino que es una consecuencia de las políticas de prestación de créditos hipotecarios durante el periodo de expansión económica de España y su desaforado crecimiento urbanístico.

En el presente estudio hemos tomado como referencia las cinco principales entidades bancarias del país, tanto por volumen de activos como por su participación en el mercado inmobiliario de Madrid (Banco Santander, BBVA, CaixaBank, Bankia y Banco Sabadell). El número de viviendas que sus inmobiliarias gestionan y además tienen a la venta en la ciudad de Madrid es 734. El reparto por inmobiliarias (Figura 5) queda encabezado por Solvia con 385 viviendas en venta $(52,46 \%)$, seguida por Haya Real Estate con $138(18,80 \%)$, ANIDA con 90 (12,26\%), Servihabitat con $85(11,58 \%)$ y por último, Altamira con $36(4,90 \%)$. Por lo tanto, más del $50 \%$ de las viviendas en venta están gestionadas por la inmobiliaria del Banco Sabadell, que es la encargada de la mayor parte de la bolsa de viviendas en todos los distritos a excepción de Chamartín, Retiro y Moncloa-Aravaca. Además, es junto a Servihabitat, la única con presencia en todos los distritos. La importante representación de esta inmobiliaria se debe a la adjudicación, por parte de la Sareb, de la gestión de una significativa porción del paquete de viviendas propiedad de Bankia, antigua Caja Madrid, y principal beneficiaria del rescate bancario (Pellicer, 2014).

Figura 5. Reparto de la bolsa de viviendas usadas por distritos e inmobiliarias bancarias.

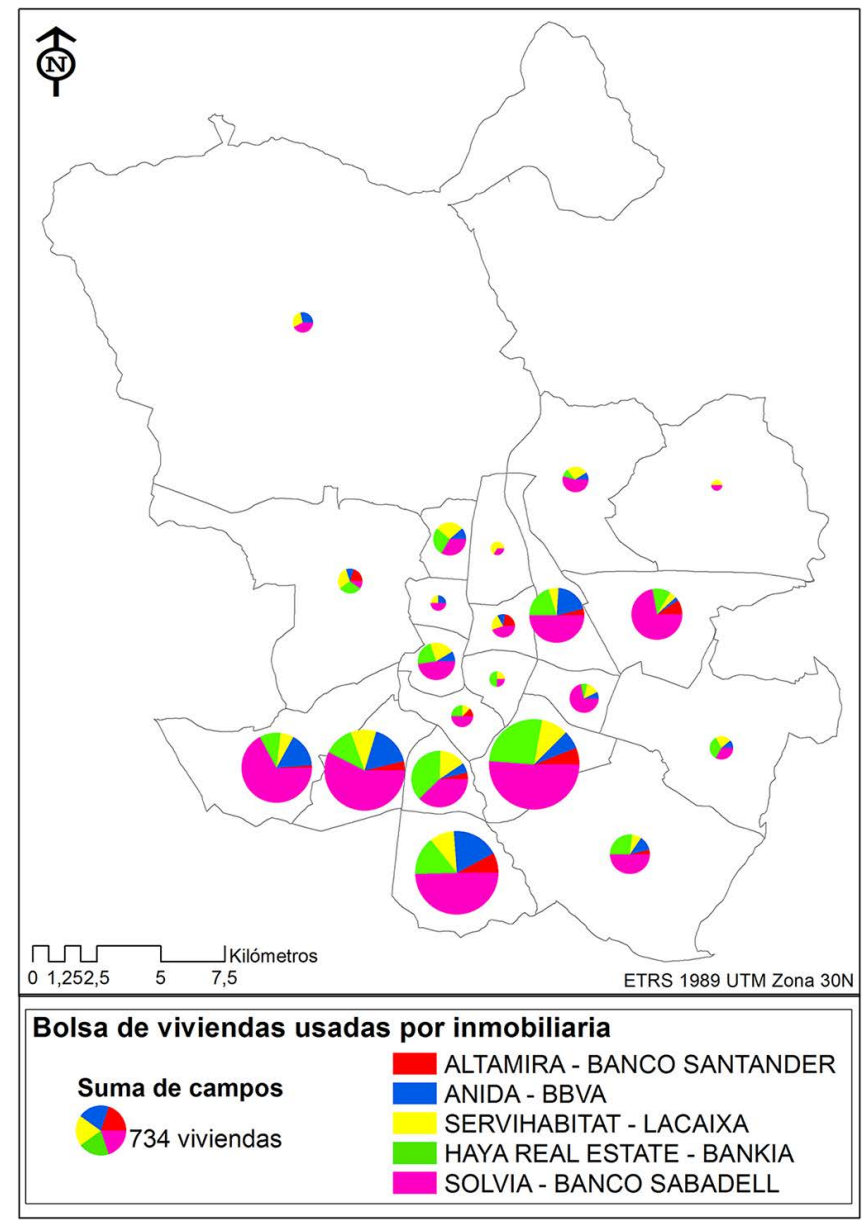

Fuente: inmobiliarias Altamira, ANIDA, Servihabitat, Haya Real Estate y Solvia. Elaboración propia. 
Si examinamos su reparto por distritos, comprobamos como su posicionamiento en el mercado de vivienda surge de una situación sobrevenida, y no fruto de la inversión meditada en busca de rentabilidad. De hecho, la mayoría de las viviendas en venta se sitúan en los distritos del sur de Madrid, es decir, aquellos que albergan la población con menor poder adquisitivo y dónde se registra un menor precio de venta de la vivienda usada, muy inferior a la media de la capital. Los distritos de Puente de Vallecas (18,39\%), Villaverde (15,67\%) y Carabanchel (14,71\%) suman casi el 50\% de los inmuebles en venta. Paradójicamente, estas secciones se sitúan en posiciones intermedias en cuanto al número de transacciones inmobiliarias tanto de viviendas nuevas como usadas, aunque muy alejadas de la cabeza. Por otro lado, distritos centrales y septentrionales con un mayor nivel socioeconómico como Fuencarral-El Pardo, Retiro, Chamberí, Chamartín y Barajas no llegan ni a representar, en conjunto, el 3\% del total de viviendas en venta.

En suma, el precio de todos los activos en venta a través de las inmobiliarias alcanza los 95.445.195 euros, gracias a un precio medio de la vivienda usada de 130.034,33 euros. Por distritos (Figura 6a), se repite el patrón, esto es, los distritos meridionales como Puente de Vallecas (12,9 millones de $€$ ), Carabanchel $(12,7$ millones de $€$ ) y Latina (10,5 millones de $€$ ) superan, cada uno de ellos, una valoración conjunta de los inmuebles en venta de diez millones de euros, a pesar de que el precio medio de las viviendas no supera en ningún caso el promedio madrileño. Este hecho se debe principalmente a que la bolsa de pisos en venta tiene un gran tamaño, no obstante, estos distritos ocupan tres de los cuatro primeros puestos en este particular ranking.

Figura 6. a) Distribución y valor de la bolsa de viviendas usadas en poder de los bancos por distritos (izquierda). b) Diferencias entre el precio del $\mathrm{m}^{2}$ de vivienda usada fijado por los bancos y la media del mercado (derecha).

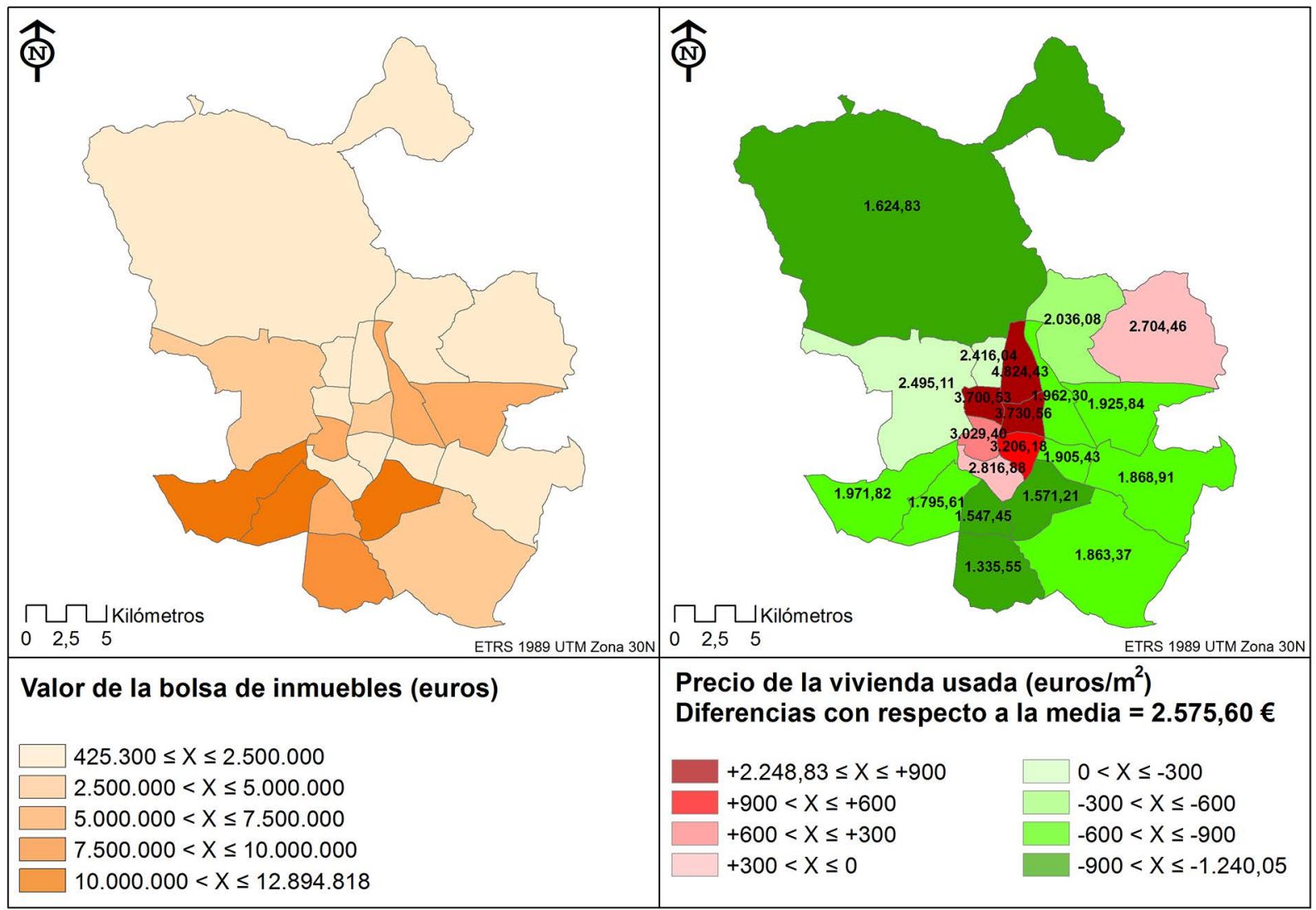

Fuente: inmobiliarias Altamira, ANIDA, Servihabitat, Haya Real Estate y Solvia. Elaboración propia.

Si tenemos en cuenta la relación entre precio y superficie de los inmuebles en poder de los bancos, el precio medio del metro cuadrado se sitúa en 1.841,56 euros, es decir, 734,04 euros por debajo del promedio de Madrid para el mismo tipo de vivienda. Esta importante diferencia de precios puede estar provocada por múltiples factores, entre ellos destacan el estado de los inmuebles y su superficie. En este último punto se aprecian notables diferencias puesto que el promedio de las viviendas en manos de los 
bancos se sitúa en $68,16 \mathrm{~m}^{2}$, mientras que la cifra para toda la ciudad de Madrid alcanza los $86 \mathrm{~m}^{2}$. Este último registro sólo lo supera el 8,99\% de la muestra.

Como podemos ver en la Figura 6b, Chamartín es el distrito de Madrid más caro para comprar vivienda usada a las entidades bancarias $\left(4.824,43 € / \mathrm{m}^{2}\right)$, seguido de Salamanca $\left(3.730,56 € / \mathrm{m}^{2}\right)$, Chamberí $\left(3.700,54 € / \mathrm{m}^{2}\right)$, Retiro $\left(3.206,18 € / \mathrm{m}^{2}\right)$ y Centro $\left(3.029,40 € / \mathrm{m}^{2}\right)$. Este bloque de secciones centrales mantiene por tanto los precios más altos, siguiendo la tendencia general del mercado (a excepción de Moncloa-Aravaca), aunque con variaciones en cuanto a la posición de los mismos (propiciadas por las condiciones particulares de cada inmueble y el tamaño ínfimo de la muestra dentro de estas secciones). Estos distritos representan, sin embargo, un escaso 5,9\% de la muestra, el mismo peso que el distrito de San Blas-Canillejas en solitario, aunque con una bolsa de inmuebles que multiplica por 2,56 el valor de la correspondiente al distrito del extremo oriental de la capital.

Por debajo del precio medio de vivienda usada fijado por el mercado, que recordemos era de 2.575,60 euros $/ \mathrm{m}^{2}$, encontramos el resto de distritos a excepción de Arganzuela $\left(2.816,88 € / \mathrm{m}^{2}\right)$ y Barajas $(2.704,46$ $€ / \mathrm{m}^{2}$ ). Es precisamente en los distritos con un precio del metro cuadrado más barato dónde se concentra buena parte de la oferta de las inmobiliarias bancarias. De hecho, en los cinco distritos con un menor precio (Villaverde, Usera, Puente de Vallecas, Fuencarral-El Pardo y Carabanchel) se localiza el 56,9\% de las viviendas gestionadas para su venta por las inmobiliarias. Además, se trata de los únicos distritos que no logran superar ni el precio medio fijado en Madrid por el mercado ni el establecido por los inmuebles analizados en este trabajo, es decir, aquellos que son propiedad de los bancos.

Tabla 1. Tamaño de la vivienda usada, precio del $\mathrm{m}^{2}$ y edad de la edificación.

\begin{tabular}{|c|c|c|c|}
\hline Distrito & Tamaño de la vivienda* & $\begin{array}{c}\text { Precio del } \\
\text { metro cuadrado** }\end{array}$ & $\begin{array}{c}\text { Edad } \\
\text { de la edificación }\end{array}$ \\
\hline Fuencarral - El Pardo & 2,71 & $-778,44$ & 47,29 \\
\hline Hortaleza & $-12,36$ & $-481,63$ & 47,30 \\
\hline Moncloa - Aravaca & 9,70 & $-323,59$ & 25,50 \\
\hline Ciudad Lineal & $-7,76$ & $-128,76$ & 48,67 \\
\hline Villaverde & $-1,77$ & $-26,53$ & 51,70 \\
\hline Salamanca & $-2,11$ & 84,87 & 49,11 \\
\hline Tetuán & $-25,83$ & 88,23 & 58,00 \\
\hline Usera & $-11,49$ & 94,73 & 55,63 \\
\hline Retiro & $-31,25$ & 102,72 & 44,50 \\
\hline San Blas - Canillejas & $-19,26$ & 114,05 & 50,40 \\
\hline Vicálvaro & $-12,33$ & 133,20 & 53,22 \\
\hline Puente de Vallecas & 0,53 & 203,85 & 51,23 \\
\hline Moratalaz & $-3,21$ & 213,43 & 48,21 \\
\hline Centro & 2,22 & 235,52 & 94,00 \\
\hline Carabanchel & $-2,21$ & 372,63 & 50,44 \\
\hline Latina & $-2,29$ & 481,80 & 49,79 \\
\hline Villa de Vallecas & $-10,15$ & 487,04 & 44,58 \\
\hline Chamberí & 48,25 & 515,00 & 79,25 \\
\hline Barajas & $-17,00$ & 555,31 & 17,50 \\
\hline Arganzuela & $-27,50$ & 634,07 & 75,63 \\
\hline Chamartín & 16,00 & 1289,66 & 44,67 \\
\hline \multicolumn{4}{|c|}{ * Diferencia del promedio de la muestra con respecto a la media del distrito (metros) } \\
\hline ** Diferencia del prom & estra con resp & nedia del distr & \\
\hline
\end{tabular}

Fuente: Ayuntamiento de Madrid. Elaboración propia.

En el estudio del nivel de precios establecidos por las entidades bancarias y su comparación con el resto del mercado, podemos observar comportamientos extraños en la asignación de los mismos. Sólo en cinco de los veintiún distritos que componen Madrid, las inmobiliarias bancarias están vendiendo 
sus pisos por debajo del precio de mercado: Fuencarral-El Pardo $\left(-778,44 € / \mathrm{m}^{2}\right)$, Hortaleza $(-481,63 € /$ $\left.\mathrm{m}^{2}\right)$, Moncloa-Aravaca $\left(-323,59 € / \mathrm{m}^{2}\right)$, Ciudad Lineal $\left(-128,76 € / \mathrm{m}^{2}\right)$ y Villaverde $\left(-26,53 € / \mathrm{m}^{2}\right)$. Estos distritos se ubican principalmente en el extremo septentrional, con la excepción de Villaverde, dónde las condiciones de compra-venta se asemejan más al promedio. La edad media de la edificación roza el medio siglo, al igual que el valor registrado en las 734 viviendas (52,16 años), con la excepción del distrito Moncloa-Aravaca que presenta una edad media de la edificación de 25,5 años.

En el resto de los distritos, los bancos están vendiendo sus inmuebles a un precio superior a la media fijada por el mercado en cada uno de ellos. Esta horquilla va desde los 84,87 euros $/ \mathrm{m}^{2}$ por encima del promedio (Salamanca), hasta los 1.289,66 euros $/ \mathrm{m}^{2}$ (Chamartín). Las características generales de estos inmuebles se podrían resumir en viviendas pequeñas y muy antiguas. No obstante, la superficie media de las viviendas en poder de los bancos sólo supera el promedio del distrito en Puente de Vallecas, Centro, Chamberí y Chamartín, alcanzando valores destacables sólo en estos dos últimos (aunque con una muestra muy exigua). Todos los distritos presentan una bolsa de pisos muy antiguos, alrededor de los 50 años, a excepción de aquellas secciones de reciente expansión como Barajas (17,5 años) u otros distritos céntricos como Arganzuela, Chamberí o Centro, dónde la edad de la edificación en venta es muy superior, aunque en consonancia con el promedio existente.

En cuanto a la distribución interna de los inmuebles, podemos comprobar como el modelo de vivienda más repetido es el compuesto por tres habitaciones y un baño. Esta configuración está presente en 355 domicilios, es decir, el 48,36\% del total. Le sigue la distribución compuesta por dos habitaciones y un baño, presente en 192 viviendas, y aquellos inmuebles con una habitación y un baño, que son sólo 76. El resto de configuraciones tienen escasa representación.

Cabe destacar que en los distritos de la almendra central se ubican mayoritariamente aquellas viviendas compuestas por dos habitaciones y un baño, lo cual no se corresponde con un tamaño de la vivienda inferior. De hecho, en los distritos Centro $\left(80,22 \mathrm{~m}^{2}\right)$, Salamanca (105,89 $\left.\mathrm{m}^{2}\right)$, Chamartín $\left(123 \mathrm{~m}^{2}\right)$ y Chamberí $\left(138,25 \mathrm{~m}^{2}\right)$ se supera holgadamente la superficie media que arroja la muestra estudiada (aunque no en todos los casos la superficie media del total de viviendas usadas), quedando sólo por debajo de ésta los distritos de Retiro $\left(65,75 \mathrm{~m}^{2}\right)$, Tetuán $\left(53,17 \mathrm{~m}^{2}\right)$ y Arganzuela $\left(43,5 \mathrm{~m}^{2}\right)$. Se trata por tanto de inmuebles que combinan amplia superficie con pocas estancias, lo cual puede denotar altas calidades de vivienda. Esto queda refrendado por el nivel de precios que registran estas secciones. Por el contrario, el resto de distritos muestra un predominio claro de inmuebles en venta de tres habitaciones y un baño. Si lo comparamos con la superficie de los mismos, podemos observar como aquellos que superan la media madrileña se sitúan en su extremo septentrional. Este es el caso de Ciudad Lineal (70,24 m²), Barajas (77 $\mathrm{m}^{2}$ ), Fuencarral-El Pardo $\left(94,71 \mathrm{~m}^{2}\right)$, Hortaleza $\left(98,64 \mathrm{~m}^{2}\right)$ y Moncloa-Aravaca $\left(153,7 \mathrm{~m}^{2}\right)$, aunque dentro de este grupo también encontramos el distrito de Moratalaz $\left(72,79 \mathrm{~m}^{2}\right)$. En el extremo meridional se sitúan aquellos distritos que no logran superar la media de la capital, como Villa de Vallecas $\left(66,85 \mathrm{~m}^{2}\right)$, Latina $\left(66,71 \mathrm{~m}^{2}\right)$, Usera $\left(66,51 \mathrm{~m}^{2}\right)$, Carabanchel $\left(64,79 \mathrm{~m}^{2}\right)$, San Blas-Canillejas $\left(64,74 \mathrm{~m}^{2}\right)$, Villaverde $\left(64,23 \mathrm{~m}^{2}\right)$, Vicálvaro $\left(62,67 \mathrm{~m}^{2}\right)$ y Puente de Vallecas $\left(61,53 \mathrm{~m}^{2}\right)$.

\section{CONCLUSIONES}

El posicionamiento de las entidades bancarias españolas en el mercado de vivienda usada de la ciudad de Madrid responde a una situación derivada de sus arriesgadas políticas de concesión de créditos y el advenimiento de la mayor crisis económica y financiera de los últimos tiempos. La apuesta decidida de los bancos por sumarse a la deriva especulativa del mercado inmobiliario español, ha provocado un resultado no esperado: que éstos se vean obligados a operar fuera de sus habituales espacios de negocio. Un fracaso que además ha arrastrado a toda la economía española.

Durante el periodo de bonanza económica, aquellos sectores más vulnerables de la población, es decir, personas de clase media y media-baja pudieron acceder con mayor facilidad a hipotecas para financiar su primera morada, que principalmente se concentraba en aquellos barrios y distritos madrileños que tenían los precios menos prohibitivos (espacialmente, esto se identifica con el extremo meridional de Madrid). Sólo de esta manera se podría explicar la concentración de la mayor parte de los inmuebles en los distritos del sur de la capital: aquellos que presentan los mayores índices de paro, los menores valores de renta familiar, y algunos de los índices de juventud y crecimiento demográfico más elevados de la ciudad. La afectación de las clases sociales más humildes se demuestra en que el peso relativo de la primera vivienda 
en los procedimientos de ejecución de hipotecas iniciadas representa en la Comunidad de Madrid un 91,1\% del total (Valenzuela, 2013). Por el contrario, la participación de las entidades bancarias en los distritos centrales, los más suculentos dentro del mercado inmobiliario por sus elevados precios y una menor dependencia de la demanda doméstica, es poco significativa.

Por lo tanto, la posición que la banca española ha heredado de esta coyuntura económica imprevista, la ha situado fuera de mercado, o al menos, alejada de los espacios más rentables. Si analizamos el paquete de viviendas usadas en poder de los bancos desde un punto de vista estrictamente comercial, podremos comprobar como su localización no es la más idónea para la venta, ya que en los distritos del sur se encuentran los menores registros de transacciones inmobiliarias, y además, aparecen las ciudades satélite o ciudades dormitorio como fuertes competidoras gracias a un precio inferior del metro cuadrado de vivienda y mejores calidades constructivas.

La creación de la Sareb y la aparición de las inmobiliarias bancarias ha mejorado los canales de venta, aunque su estrategia comercial se resiste a asumir la fuerte disminución del precio de la vivienda, que llegó a estar sobrevalorada un $40 \%$. Este importante descenso, que en realidad se trata de una vuelta al nivel de precios "normal", ha provocado que estos activos se ganen la calificación de "tóxicos". La demanda ha caído ostensiblemente, y aún continúa paralizada por la marcha de la economía nacional.

En la actualidad, el precio de la vivienda usada sigue cayendo en los distritos donde se posicionan los bancos, lo que viene a significar continuas pérdidas para la banca privada, y en definitiva para el Estado español, "avalista" de su rescate por parte de las instituciones europeas. La recuperación del mercado inmobiliario necesita de una simultánea mejora de la economía española, traducida en un descenso del número de parados, condición sine qua non para la reactivación de la oferta y el freno de la caída de precios.

A la espera de esta ansiada recuperación, la política de minimización de los daños provocados por la recesión económica lleva a la banca española a fijar un precio del metro cuadrado de vivienda usada superior al promedio que refleja el mercado en dieciséis de los veintiún distritos madrileños.

Figura 7. Comparación del precio del $\mathrm{m}^{2}$ de vivienda usada con el precio promedio fijado por el mercado.

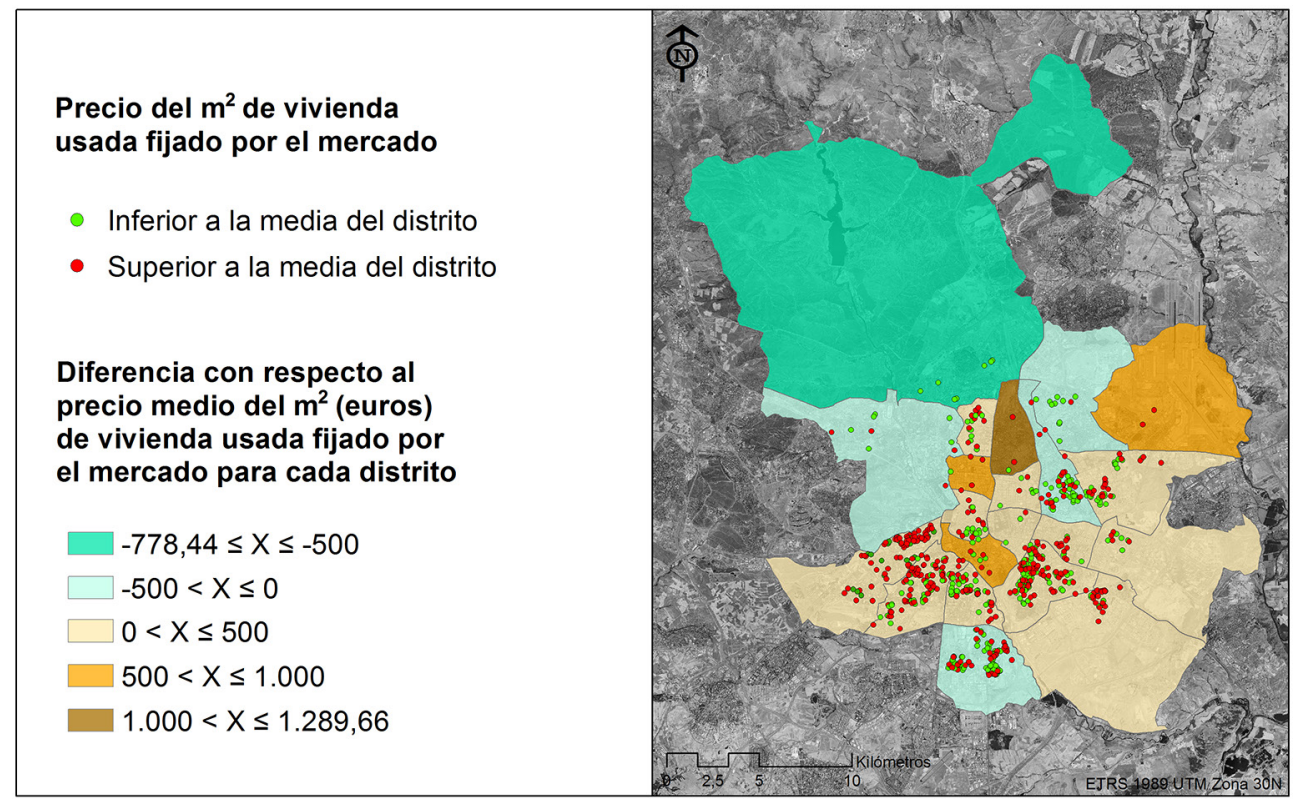

Fuente: inmobiliarias Altamira, ANIDA, Servihabitat, Haya Real Estate y Solvia. Elaboración propia.

Esta posición resulta inexplicable si además tenemos en cuenta las características de estos activos inmobiliarios. La bolsa de viviendas está compuesta, en términos generales, por inmuebles más pequeños y más antiguos que la media. De hecho, las inmobiliarias no han realizado un seguimiento exhaustivo de sus características puesto que algunos de estos pisos han pasado de mano en mano estando tapiados, por lo que su tasación se basa en criterios desconocidos para nosotros. Algo que también se demuestra en la alta variabilidad de precios dentro de inmuebles con características muy similares. Por lo tanto, a pesar 
de encontrarse en una situación poco ventajosa desde el punto de vista de las características externas (espacio urbano colindante) e internas (estado y comodidades) de los inmuebles, las entidades bancarias están actuando en contra de la lógica de mercado al situar su nivel de precios por encima de la media.

Ante una evolución negativa de las ventas, reflejada en los datos de concesión de hipotecas, las entidades bancarias han optado por no facilitar las mismas a través del abaratamiento de sus activos, a la espera de una recuperación del mercado y un incremento del valor de estos inmuebles. Sin embargo, la necesidad de vivienda sigue existiendo en la ciudad de Madrid, por lo que la proporción de domicilios alquilados sigue en aumento, debido a la imposibilidad de las familias de acometer una compra. Por el momento, el arrendamiento de inmuebles es una opción que las inmobiliarias bancarias, por regla general, no contemplan (el número de inmuebles en oferta de arrendamiento es muy inferior a aquellos destinados a su venta) por los posibles problemas derivados con los inquilinos. El resultado de esta política es una bolsa de viviendas que no logra disminuir y un aumento paralelo del número de viviendas vacías.

Sin embargo, la necesidad social de vivienda y la simultánea disponibilidad de inmuebles vacíos, crea una situación paradójica que la Administración Local trata de resolver mediante la gestión de alquileres sociales en viviendas cedidas por la banca. En otros escenarios de la geografía española, las reticencias de los bancos a favorecer la ocupación de estas viviendas han obligado a las corporaciones locales a intervenir mediante sanciones a las entidades bancarias (Vallespín, 2013). La Administración debe aprovechar esta oportunidad de crear un parque público de viviendas sociales destinadas al alquiler, que se nutra de los activos inmobiliarios que la banca maneja.

En resumen, se puede considerar que la banca tiene una posición fuerte dentro del mercado inmobiliario, tanto por el volumen de su bolsa de viviendas como por el espacio que ocupan (los distritos que más crecen). A tenor de los datos, la ciudad de Madrid es una de esas áreas-problema, dónde la densidad de desahucios degrada el paisaje urbano (Méndez y Plaza, 2016), y la actuación posterior de las entidades bancarias agrava la situación. Si la mejora de los datos macroeconómicos se traduce en un aumento de la capacidad de compra (o endeudamiento) de las familias, la oferta y la demanda aumentarán, y con ella los precios, reduciendo las pérdidas del sector bancario y el número de viviendas vacías. Su actual estrategia comercial sigue una línea conservadora, manteniendo los precios por encima de lo que dicta el mercado y reteniendo unos inmuebles que son necesarios en nuestra actual coyuntura de emergencia social.

\section{AGRADECIMIENTOS}

Esta investigación está financiada por el Ministerio de Educación, Cultura y Deporte, a través del Programa de Formación del Profesorado Universitario (FPU). Referencia FPU13/00990.

\section{REFERENCIAS}

Ayuntamiento de Madrid (2008). Barómetro de Economía de la Ciudad de Madrid (16). Madrid: Ayuntamiento de Madrid. Recuperado de http://www.madrid.es/UnidadesDescentralizadas/UDCObservEconomico/ BarometroEconomia/2008/Cap\%C3\%ADtulos/Ficheros/Abril/II.Equilibrioterritorial.pdf

Calderón, B. (2002). Ganar tamaño y territorio: Fusiones de empresas y nuevos yacimientos de actividad en el sector inmobiliario español. Investigaciones Geográficas, (28), 71-88. http://dx.doi.org/10.14198/ INGEO2002.28.04

Calvo, A. y Martín de Vidales, I. (2014). Crisis y cambios estructurales en el sector bancario español: Una comparación con otros sistemas financieros. Estudios de Economía Aplicada, 32(2), 535-566. Recuperado de http://www.revista-eea.net/documentos/32205.pdf

Cartociudad. (2015). Centro Nacional de Información Geográfica. Recuperado de http://www.cartociudad. es/portal/

Duque, J.C., Velásquez, H. y Agudelo, J. (2011). Infraestructura pública y precios de vivienda: una aplicación de regresión geográficamente ponderada en el contexto de precios hedónicos. Ecos de Economía, (33), 95-122. Recuperado de http://publicaciones.eafit.edu.co/index.php/ecos-economia/ article/view/480

Inmobiliaria Altamira. (2015). Banco Santander. Recuperado de https://www.altamirainmuebles.com/ Inmobiliaria ANIDA. (2015). BBVA. Recuperado de https://www.bbvavivienda.com/ 
Inmobiliaria Haya Real Estate. (2015). Bankia. Recuperado de http://www.haya.es/

Inmobiliaria Servihabitat. (2015). Caixabank. Recuperado de http://www.servihabitat.com/

Inmobiliaria Solvia. (2015). Banco Sabadell. Recuperado de http://www.solvia.es/

Instituto Nacional de Estadística [INE]. (2007). Encuesta de Población Activa. Madrid: Instituto Nacional de Estadística.

Instituto Nacional de Estadística [INE]. (2008). Contabilidad Nacional de España. Madrid: Instituto Nacional de Estadística.

Instituto Nacional de Estadística [INE]. (2011). Censo de Población y Viviendas. Madrid: Instituto Nacional de Estadística.

Jiménez, V. (2015). Mercado del alquiler en la ciudad de Cáceres. Estudio de la oferta inmobiliaria y la demanda universitaria. Ería: Revista cuatrimestral de geografía, (96), 33-54. http://dx.doi.org/10.17811/ er.96.2015.33-54

Méndez, R. y Prada-Trigo, J. (2014). Crisis, desempleo y vulnerabilidad en Madrid. Scripta Nova. Revista electrónica de geografía y ciencias sociales, XVIII(474). Recuperado de http://www.ub.edu/geocrit/sn/ $\underline{\text { sn- } 474 . h t m}$

Méndez, R. y Plaza, J. (2016). Crisis inmobiliaria y desahucios hipotecarios en España: una perspectiva geográfica. Boletín de la Asociación de Geógrafos Españoles, (71), 99-127. Recuperado de http://www. age-geografia.es/ojs/index.php/bage/article/viewFile/2276/2161

Naredo, J.M. (2009). La cara oculta de la crisis. El fin del boom inmobiliario y sus consecuencias. Revista de Economía Crítica, (7), 118-133. Recuperado de http://revistaeconomiacritica.org/sites/default/files/ revistas/n7/6_la_cara_oculta_de_la_crisis.pdf

Ortega, E., Rubio, M. y Thomas, C. (2011). House purchase versus rental in Spain. En AA.VV. (Ed.), Encuentro de Economía Pública (pp. 1-28). Málaga, España: Banco de España.

Pellicer, L. (3 de noviembre de 2014). El banco malo adjudica al Sabadell la gestión de 42.900 activos. El País. Recuperado de http://economia.elpais.com/economia/2014/11/03/actualidad/1415045038 626129. $\underline{\mathrm{html}}$

Real Decreto 1559/2012, por el que se establece el régimen jurídico de las sociedades de gestión de activos. Boletín Oficial del Estado, Madrid, España (15 de noviembre de 2012).

Sistema de Información Territorial Nomecalles. (2015). Comunidad de Madrid. Recuperado de http://www. madrid.org/nomecalles/

Sociedad de Gestión de Activos Procedentes de la Restructuración Bancaria S.A. [Sareb] (2014). Informe anual 2014. Madrid: SAREB. Recuperado de https://www.sareb.es/es-es/accionistas-e-inversores/ Documents/Informe\%20Anual\%202014\%20v2.pdf

Street View Google Maps. (2015). Google. Recuperado de https://maps.google.es/

Temes, R. (2014). Valoración de la vulnerabilidad integral en las áreas residenciales de Madrid. EURE, 40(119), 119-149. Recuperado de http://dx.doi.org/10.4067/S0250-71612014000100006.

Valenzuela, M. (2013). La vivienda tras la "burbuja": grandes retos para un futuro incierto. En Fundación Encuentro (Eds), Informe España 2013 (pp. 291-425). Madrid: Fundación Encuentro.

Vallespín, I. (31 de diciembre de 2013). Terrassa multa a tres bancos por tener pisos vacíos durante más de dos años. EL PAÍS. Recuperado de http://ccaa.elpais.com/ccaa/2013/12/30/catalunya/1388428224_184332. $\underline{\mathrm{html}}$.

Vinuesa, J., De la Riva, J.M. y Palacios, A.J. (2009). Política de vivienda y urbanismo. Ciudad y Territorio. Estudios Territoriales, XLI(161-162), 505-520. Recuperado de http://www.uam.es/personal_pdi/ filoyletras/juvian/documentos/DOC\%20Y\%20PUBLIC/2009\%20Politica\%20de\%20vivienda\%20 y\%20urbanismo\%20cyt.pdf 